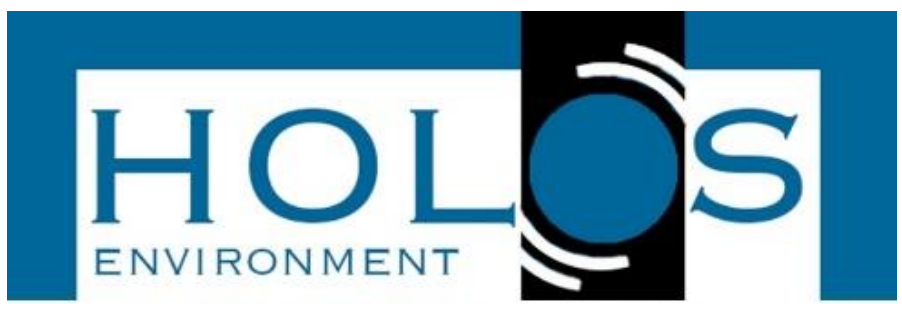

\title{
DESAFIOS E OPORTUNIDADES NA UTILIZAÇÃO SUSTENTÁVEL DOS RECURSOS NATURAIS NO DISTRITO DE MASSINGA, PROVÍNCIA DE INHAMBANE-MOÇAMBIQUE
}

\section{CHALLENGES AND OPPORTUNITIES IN THE SUSTAINABLE USE OF NATURAL RESOURCES IN THE DISTRICT OF MASSINGA, INHAMBANE PROVINCE-MOZAMBIQUE}

\author{
Angelo Lourenco Guimaraes ${ }^{1}$
}

Artigo recebido em: 20/12/2018 e aceito para publicação em: 18/06/2019.

DOI: http://dx.doi.org/10.14295/holos.v19i3.12325

Resumo: No presente artigo analisa-se os desafios e oportunidades da utilização de Recursos Naturais no Distrito de Massinga, Província de Inhambane, com destaque para o calcário, olhando para os Objectivos do Desenvolvimento Sustentável. Em termos de Materiais e Métodos, recorreu-se à consulta bibliografia relevante que aborda a gestão dos recursos naturais no País (Leis nacionais) e outros documentos normativos, como por Exemplo a Constituição da República de Moçambique. Segundo o Plano para o Desenvolvimento do Distrito 2017-2026 (PDD), o Distrito possui inúmeros recursos naturais, sendo de destacar os minerais. Os recursos minerais, neste caso concreto o calcário, quando bem explorado constituem fonte de economia comunitário contribuindo para o desenvolvimento do Distrito e em particular para a comunidade de Mambadine. A extracção de recursos naturais faz parte da história humana. Contudo, muito tem se discutido sobre como conciliar a crescente necessidade humana de obter recursos, com a possibilidade de os mesmos virem a se esgotar. $O$ estudo revela que o Distrito de Massinga, não é rica em recursos naturais, dada a sua localização numa bacia sedimentares recente. Existe sim disponíveis alguns recursos a serem capitalizados, o exemplo de calcários e Saibro, assim como os florestais que são usados em grande medida para a construção de habitações à nível Distrital e Provincial. O aproveitamento económico dos recursos naturais traz consigo o aumento da renda familiar para além de produzir consequências ambientais que exigem soluções integradas em vários campos do conhecimento, ou seja, a gestão ambiental integrada.

Palavras-chave: Recurso Natural. Gestão de Recursos Naturais. Desenvolvimento Sustentável.

Abstract: This article analyzes the challenges and opportunities of the use of Natural Resources in the District of Massinga, Province of Inhambane, highlighting the limestone, looking for the Sustainable Development Objectives. In terms of Materials and Methods, reference was made to relevant literature that addresses the management of natural resources in the Country (national laws) and other normative documents, such as the Constitution of the Republic of Mozambique. According to the District Development Plan for the District 2017-2026 (PDD), the District has many natural resources, and minerals stand out. Mineral resources, in this case concrete limestone, when well exploited constitute a source of community economy contributing to the development of the District and in particular to the community of Mambadine. The extraction of natural resources is part of human history. However, much has been discussed about how to reconcile the growing human need for resources, with the potential for them to be depleted. The study reveals that the Massinga District is not rich in natural resources, given its location in a recent sedimentary basin. There are, however, some resources to be capitalized, examples of limestone and gravel, as well as forestry that are used to a great extent for

${ }^{1}$ Universidade Pedagogica (UP). Maputo, Mocambique E-mail: (angelolouguimaraes@gmail.com 
the construction of housing at District and Provincial levels. The economic exploitation of natural resources brings with it an increase in family income, in addition to producing environmental consequences that require integrated solutions in various fields of knowledge, that is, integrated environmental management.

Keywords: Natural Resource. Natural Resource Management. Sustainable development.

\section{INTRODUÇÃO}

O Meio Ambiente e Desenvolvimento Sustentável são temas que paulatinamente conquistaram uma importante posição na sociedade e, hoje, são objecto de estudo de diversas ciências nos diferentes subsistemas de ensino. A preocupação pelos impactos ambientais vem criando um crescente interesse nos últimos tempos pela importância que é dada à gestão ambiental e preservação de recursos naturais com vista a garantir o Desenvolvimento Sustentável (DS), pelo que se torna necessário aprofundar o conhecimento dos efeitos negativos da actividade humanas obre o meio ambiente, com a finalidade de prevenir ou reduzir os seus impactos sobre o meio ambiente.

A rápida e contínua expansão da urbanização decorrente do desenvolvimento da própria sociedade, dos sectores industrial e de serviços, do crescimento populacional, entre outros, tem aumentado a demanda e pressão sobre os recursos naturais, em especial, por recursos minerais de emprego directo na construção civil fomentando uma actividade extrativa transformadora do meio ambiente, induzindo a sua contínua degradação.

A extracção dos recursos minerais é uma actividade economicamente importante no nosso País e em particular nas comunidades rurais porque oferece materiais de aplicação para os diferentes fins. A extracção de recursos naturais faz parte da história humana. Contudo, muito tem se discutido sobre como conciliar a crescente necessidade humana de obter recursos, com a possibilidade de os mesmos virem a esgotar. $\mathrm{O}$ aproveitamento económico dos recursos naturais traz consigo o aumento da renda familiar para além de produzir consequências ambientais que exigem soluções integradas em vários campos do conhecimento, ou seja, a gestão ambiental integrada

Segundo CUNHA, (1982). Citado por (GEOUSP, 2006) Recurso natural é qualquer elemento ou aspecto da natureza que possa ser explorado pelo homem, direta ou indiretamente, ou que esteja em demanda. Em verdade, a etimologia do 
termo recurso já traz, implicitamente, a ideia de algo que está em demanda. O termo é designado como algo a que se recorre para resolver qualquer das necessidades do homem. Na tentativa de se encontrar uma definição cabal, (GEOUSP, 2006) afirma que Recurso natural pode ser definido como qualquer elemento ou aspecto da natureza que esteja em demanda, seja passível de uso ou esteja sendo usado direta ou indiretamente pelo homem como forma de satisfação de suas necessidades físicas e culturais, em determinado tempo e espaço. Portanto, os recursos naturais são componentes da paisagem geográfica, materiais ou não, que ainda não sofreram importantes transformações pelo trabalho humano e cuja própria gênese independe do homem, mas aos quais foram atribuídos, historicamente, valores econômicos, sociais e culturais e só podem ser compreendidos a partir da relação Homem-Natureza. Se, por um lado, os recursos naturais ocorrem e distribuem-se no estrato geográfico segundo uma combinação de processos naturais, por outro, sua apropriação ocorre segundo valores sociais.

Diante do exposto acima, chega-se a uma conclusão de que palavra recurso significa algo a que se possa recorrer para a obtenção de alguma coisa." Portanto, o homem recorre aos recursos naturais, isto é, aqueles que estão na Natureza, para satisfazer suas necessidades materiais, sociais, físicas, entre outras. Isto significa que recurso pode ser: (a) Componente do ambiente (relacionado com frequência à energia) que é utilizado por um organismo e (b) qualquer coisa obtida do ambiente vivo e não-vivo para preencher as necessidades e desejos humanos.

Os recursos naturais, se após seu uso podem ser renovados, isto é, voltarem a estar disponíveis, são renováveis, caso contrário são não renováveis. São exemplos de recursos renováveis a flora, fauna naturais e todos os ecossistemas cultivados. Já os recursos naturais não renováveis, são os que não podem ser produzidos, embora possam a longo prazo serem substituídos por outros, como por exemplo o petróleo substituindo o carvão.

\section{MATERIAIS E MÉTODOS}

A pesquisa baseou-se na pesquisa qualitativa que pode ser vista como uma metodologia de pesquisa não estruturada e exploratória. Para o efeito recorre-se à Revisão Bibliográfica, que consistiu na leitura de revistas, artigos, manuais e outros documentos que versam sobre o assunto, com maior enfoque no Plano para o De- 
senvolvimento do Distrito de Massinga 2017-2026 (PDD), o perfil do Distrito de Massinga (2014), o Plano Quinquenal do Governo (2015-2019) e Objectivos do Desenvolvimento Sustentável (ODS). Recorreu-se também ao Método Cartográfico, onde foi consultada a Carta de solos 1:5000 da Província de Inhambane.

\subsection{Localização da Área de Estudo}

O Distrito de Massinga está situado na zona central da província de Inhambane, tendo como limites, a Sul os distritos de Funhalouro e Morrumbene, a oeste o distrito de Funhalouro, a Norte e Nordeste o distrito de Vilankulo, e a Este o oceano Índico.

A superfície do Distrito1 é de 7.426 km2 e a sua população está estimada em 199 mil habitantes à data de $1 / 7 / 2012$. Com uma densidade populacional aproximada de 26,8 hab/km2, prevê-se que o distrito em 2020 venha a atingir os 211 mil habitantes, segundo INE (2008).

O território do Distrito de Massinga fica situado entre os paralelos $22^{\circ} 39^{\prime} \mathrm{e}$ $23^{\circ} 31^{\prime}$ de latitude sul e $34^{\circ} 54^{\prime}$ e $35^{\circ} 36^{\prime}$ de Longitude Este. Massinga está situado na zona central da província de Inhambane, tendo como limites, a Sul os distritos de Funhalouro e Morrumbene, a oeste o distrito de Funhalouro, a Norte e Nordeste o distrito de Vilankulo, e a Este o oceano Índico, (Vide Mapa 1). 
Mapa 1 - Divisão Administrativa da Província de Inhambane e Enquadramento Geográfico do Distrito de Massinga

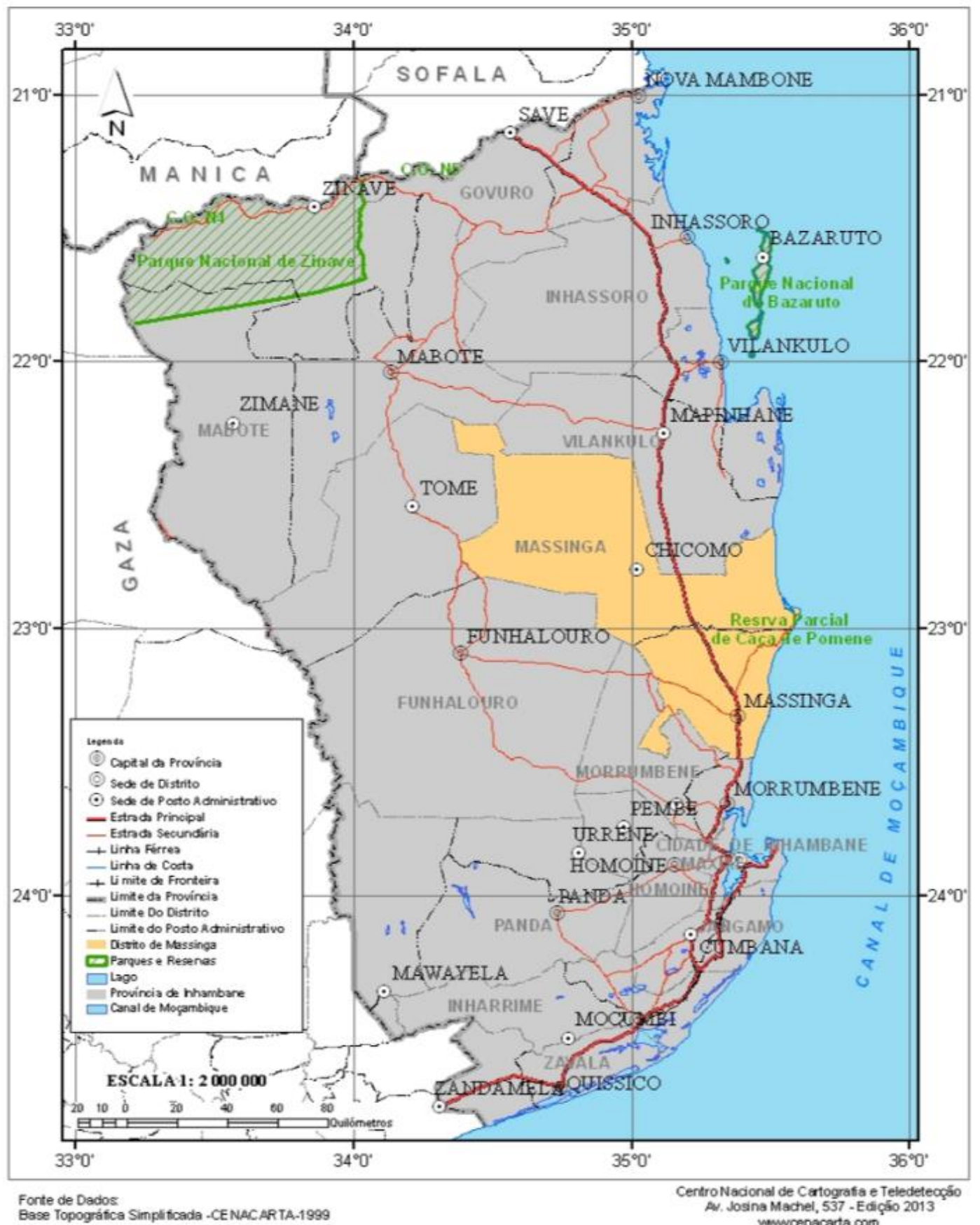

Fonte: Perfil do Distrito de Massinga (2014) 


\subsection{Desafios da Gestão de Recursos Naturais no Distrito de Massinga}

A Gestão dos Recursos Naturais (GRN) entendida como uma particularidade da gestão ambiental, preocupa-se em especial com o conjunto de princípios, estratégias e diretrizes de acções determinadas e conceituadas pelos agentes socioeconómicos, públicos e privados, que interagem no processo de uso dos recursos naturais garantindo a sustentabilidade.

É neste contexto que o Governo Distrital desenvolveu campanhas de saneamento de meio, Formação e capacitação de Comités de Gestão dos Recursos Naturais, palestras sobre queimadas descontroladas, Criação de clubes ambientais, Divulgação da Lei do Ambiente nas comunidades e palestras de Educação Ambiental, como forma de garantir uma gestão integrada dos recursos naturais (GIRN) consiste no estabelecimento de um conjunto de acções de natureza administrativa, em um determinado espaço ou unidade planificado, que considera as inter-relações entre os recursos naturais e as actividades socioeconómicas.

A preocupação em GRN, advém da necessidade que o Homem tem de apropriar-se de vários serviços ecossistêmicos que os recursos naturais oferecem para o bem-estar do Homem, como referem os estudos de HICKMAN (2001), MA (2003), GONSALVES (2011) e VONADA (2011), Ecossistema é um complexo dinâmico de comunidades de plantas, animais e micro-organismos e do meio ambiente não vivo interagindo como uma unidade funcional. Um ecossistema é uma unidade ecológica composta por uma comunidade biótica e abiótica, cujas interações produzem um sistema estável. Os seres humanos são uma parte integral dos ecossistemas, dependendo em grande parte dos serviços prestados pela biosfera e pelos seus ecossistemas para a sua sobrevivência.

A Avaliação Ecossistêmica do Milénio ONU, publicada em 2005, criou uma classificação para os serviços ambientais, dividindo-os da seguinte forma, (i) Serviços de Provisão: os produtos obtidos dos ecossistemas. Exemplos: alimentos, água doce, fibras, produtos químicos, madeira. Serviços de Regulação: benefícios obtidos a partir de processos naturais que regulam as condições ambientais. Exemplos: absorção de $\mathrm{CO}^{2}$ pela fotossíntese das florestas; controle do clima, polinização de plantas, controle de doenças e pragas. Serviços Culturais: São os 
benefícios intangíveis obtidos, de natureza recreativa, educacional, religiosa ou estético-paisagística; Serviços de Suporte: Contribuem para a produção de outros serviços ecossistêmicos: Ciclagem de nutrientes, formação do solo, dispersão de sementes, ALMEIDA (2013:17) revela que "Os recursos naturais e os serviços que os ecossistemas fornecem, são a base das actividades económicas que desenvolvemos, da qualidade de vida e da coesão social'. A preservação dos ecossistemas e, consequentemente, dos serviços ambientais por eles prestados é fundamental à existência humana.

\subsection{Desenvolvimento Sustentável}

Em 1987, a Comissão Mundial do Meio Ambiente e Desenvolvimento das Nações Unidas publicou o relatório Brundtland, que apresentou um conceito de desenvolvimento sustentável "aquele desenvolvimento que atende às necessidades do presente sem comprometer as possibilidades de as gerações futuras atenderem às suas próprias". Desenvolvimento sustentável deve, portanto, responder pilares da sustentabilidade (pilar social, económico e ambiental) para que se melhore a qualidade de vida. No contexto dos recursos naturais o desenvolvimento sustentável pode ser alcançado como uma utopia orientadora que leva ao melhoramento das formas de uso e utilização dos bens e serviços ecossistêmicos assim como o desenho de cenários.

Cenário é uma projeção sobre o futuro formulado em palavras, números e/ou mapas, apresentando desenvolvimento plausíveis em condições críticas de incerteza. "Os cenários são utilizados em situações em que os factores que influenciam o futuro são altamente incertos, incontroláveis e insuficientemente conhecidos" (Aguiar et al, in Vieira, Toledo e Júnior (orgs): 255). Segundo Aguiar et elas, (2014), no contexto ambiental podem ser utilizadas:

> Para explorar o funcionamento do sistema terrestre e os impactos das mudanças ambientais;

> Como base para discussões em vários aspectos ambientais;

> Para a tomada de decisões político-administrativos e para várias mobilizações.

As mudanças na prestação dos serviços de ecossistemas ocorrem a diferentes escalas, local, regional e global, movidas pela crescente e irreversível tendência 
da procura do bem-estar humano e redução da pobreza. No entanto, as intervenções no ambiente natural ocorrem através de promotores diretos e indiretos e promotores, conforme ilustra o esquema abaixo (Figura 2).

Figura 2 - Estrutura conceptual do Millennium Ecosytem Assessment

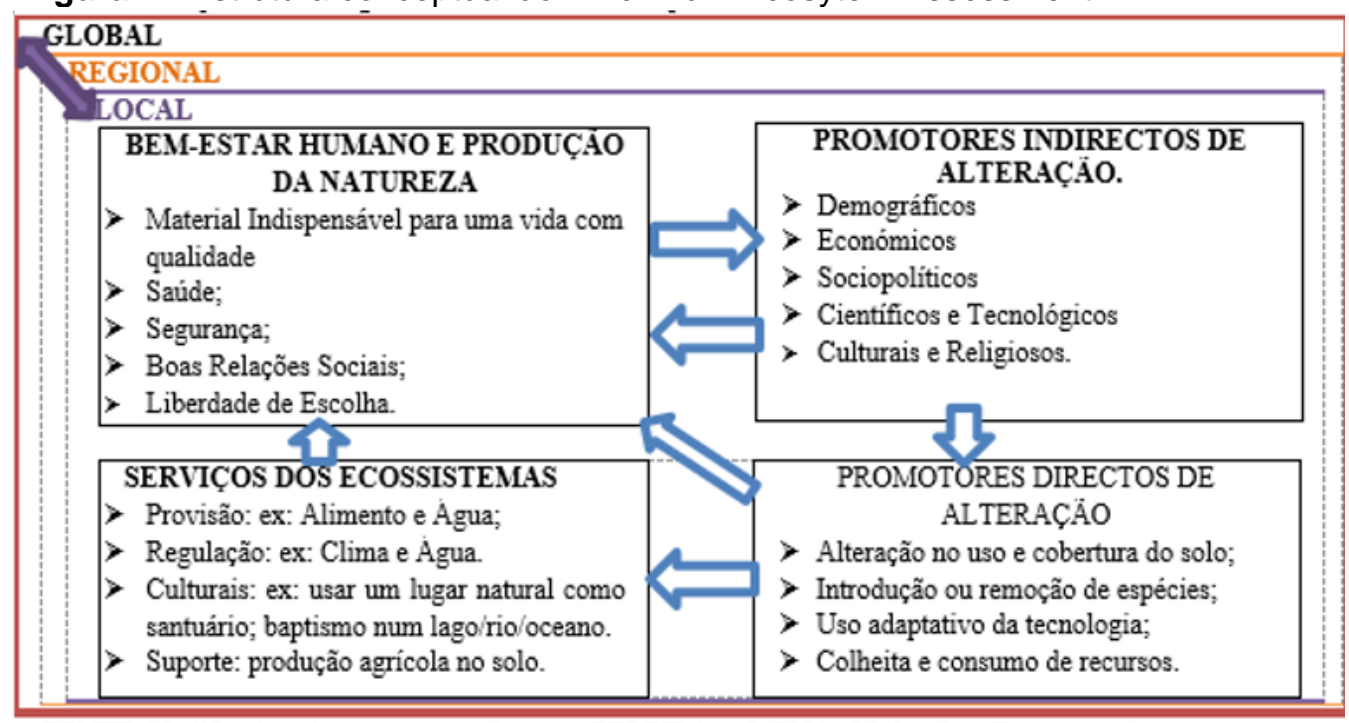

Fonte: Adaptado/autor a partir de Pereira et al. (2009)

\begin{abstract}
A valoração dos serviços dos ecossistemas pode ser usada de diferentes formas, para avaliar a contribuição total dos ecossistemas para o bem-estar humano, para compreender os incentivos que decisores individuais têm quando gerem os ecossistemas de diferentes formas e para avaliar as consequências de acções alternativas (PEREIRA et al., 2009).
\end{abstract}

Portanto, este pensamento sugere a necessidade de se pensar e introduzir continuamente no quadro da gestão de recursos naturais novos conceitos e abordagens como são os casos de cenários, "promotores de mudança", Gestão integrada dos recursos naturais (GIRN) e Gestão Participativa dos Recursos Naturais (GPRN).

\title{
3 RESULTADOS
}

\subsection{Descrição do Distrito de Massinga}

\subsubsection{Geologia}

Do ponto de vista geológico, o Distrito de Massinga, insere na bacia Sul do Save que segundo PINNA, et al., (1986:212) "o preenchimento desta bacia por sedimentos teve seu início no Cretácico e foi acompanhado por transgressões e re- 
gressões provocadas por variações climáticas e por movimentos verticais que resultaram na formação de uma serie de grabens com orientação Norte-sul (N-S). A base da Bacia é caracterizada por lavas basálticas e riolitos do Karroo. Esta região é caracterizada por rochas sedimentares do Período do Terciário e Quaternário (inferior e Superior).

\subsubsection{Relevo}

Segundo DOS MUCHANGOS (1999), "a actual estrutura físico geográfico de Moçambique resulta de um longo processo de desenvolvimento histórico da terra que teve o seu início no Pré-câmbrico e se prolonga até hoje. Este processo foi caracterizado por uma serie de fases sucessivas e alterações de orogenia, erosão e de alterações climáticas e biogénicas". A mesma fonte, afirma ainda que do ponto de vista cronológico distinguem em Moçambique, três fases principais na formação do relevo: Pré-câmbrico, Karroo e o Pós Karroo. Portanto, o relevo do Distrito de Massinga, o Distrito de Massinga é caracterizado por planícies no interior e com ocorrência de pequenas elevações do tipo dunas que variam de 100 a $200 \mathrm{~m}$ ao longo da Costa.

\subsubsection{Vegetação}

A localização geográfica de Moçambique na região florista sudanoZambeziana, condiciona em conjugação com as condições climáticas o desenvolvimento de infinitas variedades de associações vegetais hidrófilas, mesofelias e savanas arbóreas e arbustivas, portanto, nas regiões de relativa fraca pluviosidade, normalmente afastadas da costa, ocorre uma associação vegetal, vulgarmente designadas por savanas DOS MUCHANGOS (1999). A vegetação predominante no Distrito de Massinga é do tipo florestas abertas dominadas por espécies florestais para a exploração de combustível lenhoso, fauna bravia e, caracteriza-se por ocorrência de espécies florestais preciosas como Mecrusse preto, Chanfuta, Sandalo, Chacate mais para o interior do Distrito, Vide Tabela 1. 
Tabela 1 - Distribuição das principais espécies florestais no Distrito de Massinga

\begin{tabular}{|c|c|c|c|c|}
\hline $\begin{array}{c}\text { Nome } \\
\text { Português }\end{array}$ & $\begin{array}{c}\text { Nome } \\
\text { científico }\end{array}$ & $\begin{array}{c}\text { Nome } \\
\text { vernacular }\end{array}$ & $\begin{array}{l}\text { Localização/ } \\
\text { localidade }\end{array}$ & $\begin{array}{c}\text { Principal } \\
\text { uso }\end{array}$ \\
\hline $\begin{array}{c}\text { Mecrusse } \\
\text { preto }\end{array}$ & $\begin{array}{l}\text { Androstachys } \\
\text { johnsonii }\end{array}$ & Cimbirre & Chicomo & $\begin{array}{l}\text { Construcao, } \\
\text { Mobilias }\end{array}$ \\
\hline & & & & \\
\hline Chanfuta & $\begin{array}{c}\text { Atzelia } \\
\text { quanzensis }\end{array}$ & $\begin{array}{l}\text { Mugengema, } \\
\text { muoco }\end{array}$ & Chicomo & Mobilias \\
\hline & & Chilingamochi, & & \\
\hline Sandalo & africana & Mucunite & Chicomo & Mobilias \\
\hline $\begin{array}{c}\text { Chacate } \\
\text { preto }\end{array}$ & $\begin{array}{l}\text { Guibourtia } \\
\text { conjugata }\end{array}$ & Chacte & Chicomo & Mobilias \\
\hline
\end{tabular}

Fonte: (PDD 2017-2026)

\subsubsection{Caracterização Climática}

Segundo DOS MUCHANGOS (1999), da análise do comportamento do clima, conclui se que a República de Muçambique possui de uma maneira geral, um clima quente e húmido. As principais variações climáticas explicam se pela continentalidade, altitude, exposição e posição geográfica que se manifestam pelas diferentes regiões e locais entre o interior e a costa, entre os vales e as terras altas, entre o barlavento e o sotovento. O caracter predominantimente tropical do clima, revela se sobretudo pele conscidência entre o periodo de chuvas e o periodo quente e pela amplitude termica anual que é em todo o País, inferior que a diúrna. No que tange ao clima, o Distrito de Massinga é caracterizado por Clima tropical seco, no interior (influenciado pelo factor climático Continentalidade), e húmido, à medida que se caminha para a costa, com duas estações: a quente ou chuvosa que vai de Outubro a Março e a fresca ou seca de Abril a Setembro, com temperaturas médias variando entre os $18^{\circ}$ e os $30^{\circ}$.A precipitação média anual na época das chuvas (Outubro a Março) é de $1200 \mathrm{~mm}$, com maior incidência nos meses de Fevereiro e Março, em que chegam a ocorrer inundações.

\subsubsection{Pedologia}

Segundo ALMEIDA, (1959) com base na observação de perfis e de pequenas covas com cerca de $60 \mathrm{~cm}$ de profundidade, ao longo dos percursos feitos, quer de 
carro, quer a pé, os solos do Distrito de Massinga pertencem a categoria dos solos pedalféricos, isto é, aos solos das zonas em que a precipitação é superior a evaporação, propiciando desta feita ao processo de lixiviação.

Os solos pedalféricos, os solos do posto-sede de Massinga enquadram-se nos solos da faixa arenosa costeira e nos vermelhos dos Urrongas. São no geral solos vermelhos, franco-arenosos a argiloarenosos. Os argilo-arenosos ocorrem nas proximidades do rio Chicamba nos bairros Eduardo Mondlane, 21 de Abril e Chilácua respectivamente.

No geral, os solos em análise são arenosos com maior permeabilidade nas zonas de recarga. Os argilosos encontram-se nas zonas baixas, próximas de pequenas lagunas e riachos.

O interior do Distrito, apresenta solos franco-arenosos e areno-argilosos enquanto a zona do litoral apresenta solos acidentados, permeáveis favoráveis para a prática da agricultura e pecuária.

\subsubsection{Recursos Hidricos}

O distrito de Massinga é banhado pelo Oceano Índico numa extensão de $83 \mathrm{Km}$, e possui 13 rios (Mahocha, Malova, Chicamba, Rio das pedras, Chilubziane, Tevele, Chipongo, Manhenge, Hanhane, Chiguelane, Senguele, Chibanhane e Murie), e 11 Lagoas (Magumbe, cofi, Malovecua, Paindane, Tshukuri, Nhaphofo, Xiruku,Nhambzane, Txitsumanine, Queme e Nhansatane). Estes rios e lagos, são de uso directo pelas comunidades, servindo como fonte de abastecimento de água para para o uso doméstico, consumo humano e agricultura de subsistência.

O Distrito de Massinga, apresenta uma considerável diversidade de recursos naturais, embora não totalmente inventariados. Vide tabela 2. Em termos de oportunidades para o Desenvolvimento do Distrito, a Tabela 3 mostra alguns indicadores numa análise FOFA. 
Tabela 2 - Avaliação da Gestão Sustentável dos Recursos Naturais do Distrito de Massinga.

\begin{tabular}{|c|c|c|c|c|}
\hline Recursos & $\begin{array}{c}\text { Usos } \\
\text { Característicos }\end{array}$ & Zona de Ocorrência & Importância & Alguns Exemplos \\
\hline Minerais & $\begin{array}{l}\text { O Distrito possui re- } \\
\text { cursos minerais não } \\
\text { especificados e não } \\
\text { quantificados. }\end{array}$ & $\begin{array}{l}\text { Unguana Localidade de } \\
\text { Guma; Mabadine (Com } \\
\text { destaque para o Calcário), } \\
\text { Mudussua, Uiane em Li- } \\
\text { onzuane; Muronga, Mulu- } \\
\text { guiane na localidade de } \\
\text { Chicomo }\end{array}$ & Local & Calcários e Saibro \\
\hline Pedológicos & $\begin{array}{l}\text { Actividade } \\
\text { florestal }\end{array}$ & $\begin{array}{l}\text { O distrito apresenta duas } \\
\text { regiões agro-ecológicas: a } \\
\text { zona do interior, com solos } \\
\text { franco-arenosos e areno- } \\
\text { argilosos }\end{array}$ & Local & $\begin{array}{l}\text { O distrito apresenta duas } \\
\text { regiões agro-ecológicas: a } \\
\text { zona do interior, com solos } \\
\text { francoarenosos e areno- } \\
\text { argilosos }\end{array}$ \\
\hline Hídricos & $\begin{array}{l}\text { Provisão (abasteci- } \\
\text { mento de água); }\end{array}$ & $\begin{array}{l}\text { Extremo Sudeste do Distri- } \\
\text { to }\end{array}$ & Distrital & $\begin{array}{l}\text { Mahocha, Malova, Chicam- } \\
\text { ba, Rio das pedras }\end{array}$ \\
\hline $\begin{array}{l}\text { Biológicos } \\
\text { (Florestais e } \\
\text { faunísticos) }\end{array}$ & $\begin{array}{l}\text { Caça, recreação, } \\
\text { Exploração florestal } \\
\text { (madeireiros, medici- } \\
\text { nais, turismo e sócio- } \\
\text { cultural) }\end{array}$ & $\begin{array}{l}\text { Em quase toda a extensão } \\
\text { do Distrito, mas com des- } \\
\text { taque para o extremo Oci- } \\
\text { dental, nas povoações de } \\
\text { Marrilane, Balata, Cuiane, } \\
\text { N'Dimande, Mangumo, } \\
\text { Molubjane. }\end{array}$ & Provincial & $\begin{array}{l}\text { Reserva do Pomene; } \\
\text { espécies de Spitostachys } \\
\text { Africana (Sândalo), Phyllan- } \\
\text { thus SP (Chire), Androsta- } \\
\text { chys Johnsonni (Simbire), } \\
\text { Cordyla Africana (Mbon- } \\
\text { djua), Afzélia Quanzenses } \\
\text { (Chanfuta), Pterocarus An- } \\
\text { golenses (Umbila) e (Cha- } \\
\text { cate preto),. }\end{array}$ \\
\hline \multirow[t]{2}{*}{ Climáticos } & $\begin{array}{l}\text { Produção de energia } \\
\text { (Painéis solares) } \\
\text { Painéis Solares (Fo- } \\
\text { tovoltaico) }\end{array}$ & $\begin{array}{l}\text { Existência de bombas de } \\
\text { combustíveis ao longo da } \\
\text { N1 no distrito; }\end{array}$ & Local & $\begin{array}{l}\text { fonte de energia para a } \\
\text { Bombas de Combustível. }\end{array}$ \\
\hline & & & & $\begin{array}{l}\text { Cosnta a energia provida } \\
\text { dos paineis solares, abstace } \\
\text { a cerca de } 588 \text { usuários }\end{array}$ \\
\hline
\end{tabular}

Fonte: autor/2018 
Tabela 3 - Analise FOFA (Forças, Oportunidades, Fraquezas e Ameaças) do Distrito de Massinga: Alguns Indicadores

\begin{tabular}{|c|c|c|c|c|}
\hline Área & Forças & Oportunidades & Fraquezas & Ameaças \\
\hline Floresta e Fauna & $\begin{array}{l}\text { Existência recur- } \\
\text { sos florestais e } \\
\text { faunística. }\end{array}$ & $\begin{array}{l}\text { Operadores nacio- } \\
\text { nais e estrangei- } \\
\text { ros; Disponibilida- } \\
\text { de para prática do } \\
\text { turismo cinegético }\end{array}$ & $\begin{array}{l}\text { Fraca fiscalização } \\
\text { Falta de aplicação do } \\
\text { período de defeso }\end{array}$ & $\begin{array}{l}\text { Seca prolongada } \\
\text { que dificulta o } \\
\text { reflorestamento e } \\
\text { abeberamento } \\
\text { dos animais }\end{array}$ \\
\hline $\begin{array}{l}\text { Abastecimento de } \\
\text { Agua e sanea- } \\
\text { mento do meio }\end{array}$ & $\begin{array}{l}\text { Recursos hídricos } \\
\text { (rios e lagoas) }\end{array}$ & $\begin{array}{l}\text { Parcerias (Missão } \\
\text { Católica de Mu- } \\
\text { vamba e JAM, } \\
\text { Water under } \\
\text { ground, AGV, a } \\
\text { lgreja Metodista } \\
\text { Unida em Moçam- } \\
\text { bique; Igreja Ema- } \\
\text { nuel) } \\
\text { Politica de Agua } \\
\text { (PA), } \\
\text { Estratégia Nacio- } \\
\text { nal dos recursos } \\
\text { Hídricos }\end{array}$ & $\begin{array}{l}\text { Insuficiência na co- } \\
\text { bertura de abasteci- } \\
\text { mento de agua; } \\
\text { Fraca capacidade de } \\
\text { exploração da água } \\
\text { do subsolo para o } \\
\text { consumo humano; } \\
\text { Falta de estabeleci- } \\
\text { mentos de venda de } \\
\text { acessórios para repa- } \\
\text { ração de fontes de } \\
\text { água, }\end{array}$ & $\begin{array}{l}\text { Seca; } \\
\text { Mudanças climá- } \\
\text { ticas; Ocorrência } \\
\text { de Água salobre. }\end{array}$ \\
\hline $\begin{array}{l}\text { Recursos Mine- } \\
\text { rais }\end{array}$ & $\begin{array}{l}\text { Existência de } \\
\text { jazigos de calcá- } \\
\text { rio, argila, saibro } \\
\text { para vários fins }\end{array}$ & $\begin{array}{l}\text { Maior procura da } \\
\text { pedra de calcário } \\
\text { para construção } \\
\text { civil }\end{array}$ & $\begin{array}{l}\text { Exploração de miné- } \\
\text { rios com recurso a } \\
\text { técnicas rudimentares } \\
\text { e prejudiciais ao am- } \\
\text { biente; } \\
\text { Existência de associ- } \\
\text { ações não licenciadas } \\
\text { na exploração de mi- } \\
\text { nérios; } \\
\text { Falta de legislação } \\
\text { para o licenciamento } \\
\text { desses recursos ao } \\
\text { do Distrito. }\end{array}$ & $\begin{array}{l}\text { Esgotamento dos } \\
\text { recursos; } \\
\text { Poluição Ambien- } \\
\text { tal }\end{array}$ \\
\hline Ambiente & \begin{tabular}{l} 
Existência de um \\
Plano de Uso de \\
Terra; \\
Clubes de ambi- \\
ente; \\
Comités de coges- \\
\multicolumn{2}{c}{ tão }
\end{tabular} & $\begin{array}{l}\text { Lei do ordenamen- } \\
\text { to do território; } \\
\text { Lei de terra; } \\
\text { Fundo Nacional do } \\
\text { Ambiente } \\
\text { (FUNAB) }\end{array}$ & $\begin{array}{l}\text { Queimadas descon- } \\
\text { troladas; } \\
\text { Abate indiscriminado } \\
\text { de espécies florestais } \\
\text { para produção de } \\
\text { lenha e carvão; } \\
\text { Frágil divulgação de } \\
\text { Lei de Terras; }\end{array}$ & $\begin{array}{l}\text { Mudanças climá- } \\
\text { ticas; } \\
\text { Extinção de es- } \\
\text { pécies faunística, } \\
\text { florestais e mari- } \\
\text { nhas }\end{array}$ \\
\hline $\begin{array}{l}\text { Redução do Im- } \\
\text { pacto das Cala- } \\
\text { midades }\end{array}$ & $\begin{array}{l}\text { Comité de gestão } \\
\text { de riscos e cala- } \\
\text { midades naturais; } \\
\text { Produção de cul- } \\
\text { turas tolerantes a } \\
\text { seca; Implemen- } \\
\text { tacão }\end{array}$ & $\begin{array}{l}\text { Existência de or- } \\
\text { ganizações não- } \\
\text { governamentais } \\
\text { que apoiam a miti- } \\
\text { gação dos efeitos } \\
\text { das calamidades }\end{array}$ & $\begin{array}{c}\text { Insuficiência de Comi- } \\
\text { té de gestão de riscos } \\
\text { e calamidades natu- } \\
\text { rais }\end{array}$ & Ciclones, Seca \\
\hline
\end{tabular}

Fonte: PDD-2017

Com uma superfície de 7.426 km2 e a sua população está estimada em 206.537 mil habitantes segundo (PDD-2017), o Distrito de Massinga conta com uma 
densidade populacional aproximada de 27,9 hab/km2, prevê-se que o distrito em 2020 venha a atingir os 211 mil habitantes.

A estrutura etária do distrito reflete uma relação de dependência económica de 1:1, isto é, por cada 10 crianças ou anciões existem 10 pessoas em idade ativa. Com uma população jovem (46\%), abaixo dos 15 anos), tem um índice de masculinidade de $79 \%$ (por cada 100 pessoas do sexo feminino existem 79 do masculino) e uma taxa de urbanização de $11 \%$, concentrada na Vila de Massinga e zonas periféricas de matriz semiurbana.

No tocante a distribuição territorial dos Recursos Naturais e a sua relação com a distribuição da população, conclui-se que o Distrito tem uma população dispersa com uma densidade baixa não enfrentando problemas de escassez de serviços Ecossistêmicos devido a fraca densidade populacional.

Os ODS visam, dentre outros, aspectos, acabar com a pobreza, promover a prosperidade e o bem-estar para todos, proteger o meio ambiente e enfrentar as mudanças climáticas. Entretanto, o Distrito de Massinga, no seu plano de Desenvolvimento do Distrito (2017-2026), não faz menção aos ODS, (Tabela 4) de forma directa, embora faça referência à formação e capacitação de Comités de Gestão dos Recursos Naturais, palestras sobre queimadas descontroladas, Criação de clubes ambientais, Divulgação da Lei do Ambiente nas comunidades e palestras de Educação. Estas acções, podem respondem aos objectivos 6, 13 e 15 do ODS, como ilustra a Tabela 5.

Tabela 4 - Analise dos Objetivos do Desenvolvimento Sustentável (ODS).

\section{Objetivos do Desenvolvimento Sustentável (ODS)}

Objetivo 6: Assegurar a disponibilidade e gestão sustentável da água e saneamento para todos.

Objetivo 13. Tomar medidas urgentes para combater a mudança do clima e seus impactos

Objetivo 15. Proteger, recuperar e promover o uso sustentável dos ecossistemas terrestres, gerir de forma sustentável as florestas, combater a desertificação, deter e reverter a degradação da terra, e estancar a perda de biodiversidade

Fonte: autores (2018) 
Tabela 5 - Principais actividades do sector de Gestão Ambiental

\begin{tabular}{lccccc}
\hline Atividades & $\mathbf{2 0 1 3}$ & $\mathbf{2 0 1 4}$ & $\mathbf{2 0 1 5}$ & $\mathbf{2 0 1 6}$ & $\mathbf{2 0 1 7}$ \\
\hline Criação de florestas comunitárias & 384 & - & - & - & - \\
Campanhas de saneamento do meio & 12 & 12 & 12 & 12 & 7 \\
Formar e capacitar Comités de Gestão dos recursos naturas & 3 & 5 & 2 & 3 & 2 \\
Realizar palestras sobre queimadas descontroladas & 9 & 10 & 12 & 8 & 5 \\
Criação de clubes ambientais & - & - & 4 & 5 & 1 \\
Divulgação da Lei de Ambiente nas comunidades & 5 & 7 & 11 & 9 & 6 \\
Realizar palestras de educação Ambiental & 7 & 9 & 11 & 9 & 7 \\
Plantar árvores de combate a erosão & - & - & 250 & - & - \\
\hline
\end{tabular}

Fonte: PDD-2017-2026

Os recursos naturais de que o Distrito dispõe proporcionam vários serviços Ecossistêmicos (provisão, produção, cultura, suporte e regulação), proporcionando assim, a redução da pobreza, das comunidades, como ilustra a tabela 6.

Tabela 6 - Serviços Ecossistêmicos, Promotores de Mudança e suas Consequências no Distrito de Massinga

\begin{tabular}{|c|c|c|c|c|}
\hline \multirow{2}{*}{$\begin{array}{c}\text { Serviço de } \\
\text { Ecossistema }\end{array}$} & \multirow{2}{*}{$\begin{array}{c}\text { Saúde bem-estar e } \\
\text { Redução da Pobreza }\end{array}$} & \multicolumn{2}{|c|}{ Promotores de Mudança } & \multirow[b]{2}{*}{ Consequências } \\
\hline & & Indirectos & Directos & \\
\hline Provisão & $\begin{array}{l}\text { Obtenção de recursos } \\
\text { lenhosos a Partir dos } \\
\text { Recursos Florestais e } \\
\text { Faunísticos }\end{array}$ & $\begin{array}{l}\text { Económicos: } \\
\text { Aumento de in- } \\
\text { vestimentos ex- } \\
\text { ternos } \\
\text { Económicos: }\end{array}$ & $\begin{array}{l}\text { Estabelecimento de plan- } \\
\text { tações florestais de es- } \\
\text { pécies de rápido cresci- } \\
\text { mento } \\
\text { Producão do tabaco em }\end{array}$ & $\begin{array}{l}\text { Redução de fonte de } \\
\text { recurso lenhoso e de } \\
\text { aquisição de alimentos } \\
\text { (frutos silvestres e caça) } \\
\text { Reducão da capacidade }\end{array}$ \\
\hline Produção & $\begin{array}{l}\text { Obtenção de alimen- } \\
\text { tos a Partir dos Re- } \\
\text { cursos pedológicos }\end{array}$ & $\begin{array}{l}\text { Aumento do pre- } \\
\text { ço do tabaco por } \\
\text { parte dos fomen- } \\
\text { tadores desta } \\
\text { cultura-MLT }\end{array}$ & $\begin{array}{l}\text { extensas áreas com apli- } \\
\text { cação excessiva de adu- } \\
\text { bos químicos }\end{array}$ & $\begin{array}{l}\text { produtiva dos solos } \\
\text { por conseguinte o sur- } \\
\text { gimento de bolsas de } \\
\text { fome nas comunidades }\end{array}$ \\
\hline Culturais & $\begin{array}{l}\text { Material indispensável } \\
\text { para uma vida com } \\
\text { qualidade e boas } \\
\text { relações sociais }\end{array}$ & Económicos: & $\begin{array}{l}\text { Alterações no uso e co- } \\
\text { bertura do solo: ocupa- } \\
\text { ção de áreas sagradas } \\
\text { por parte dos investido- } \\
\text { res. }\end{array}$ & $\begin{array}{l}\text { Deterioração dos laços } \\
\text { sociais nas comunida- } \\
\text { des }\end{array}$ \\
\hline Suporte & $\begin{array}{l}\text { Segurança e liberda- } \\
\text { de de escolha do } \\
\text { meio de transporte } \\
\text { aquático a usar }\end{array}$ & Sociopolíticos & $\begin{array}{l}\text { Uso e adaptação tecno- } \\
\text { lógica }\end{array}$ & $\begin{array}{l}\text { Reeducação dos passa- } \\
\text { geiros para barcos de } \\
\text { dimensões menores e } \\
\text { aumento para o de di- } \\
\text { mensão maior (barco } \\
\text { chambo) }\end{array}$ \\
\hline
\end{tabular}

Fonte: autor (2018)

\subsection{Oportunidades}

Massinga, apresenta uma diversidade em recursos naturais embora não expreciva do ponto de vista económico, como minerais, pedológicos, hídricos, biológicos e climáticos, sendo os mais salientes representados com um valor alto conforme o esquema abaixo. 
Esquema 1 - Rosa de avaliação da potencialidade dos Recursos Naturais no Distrito de Massinga

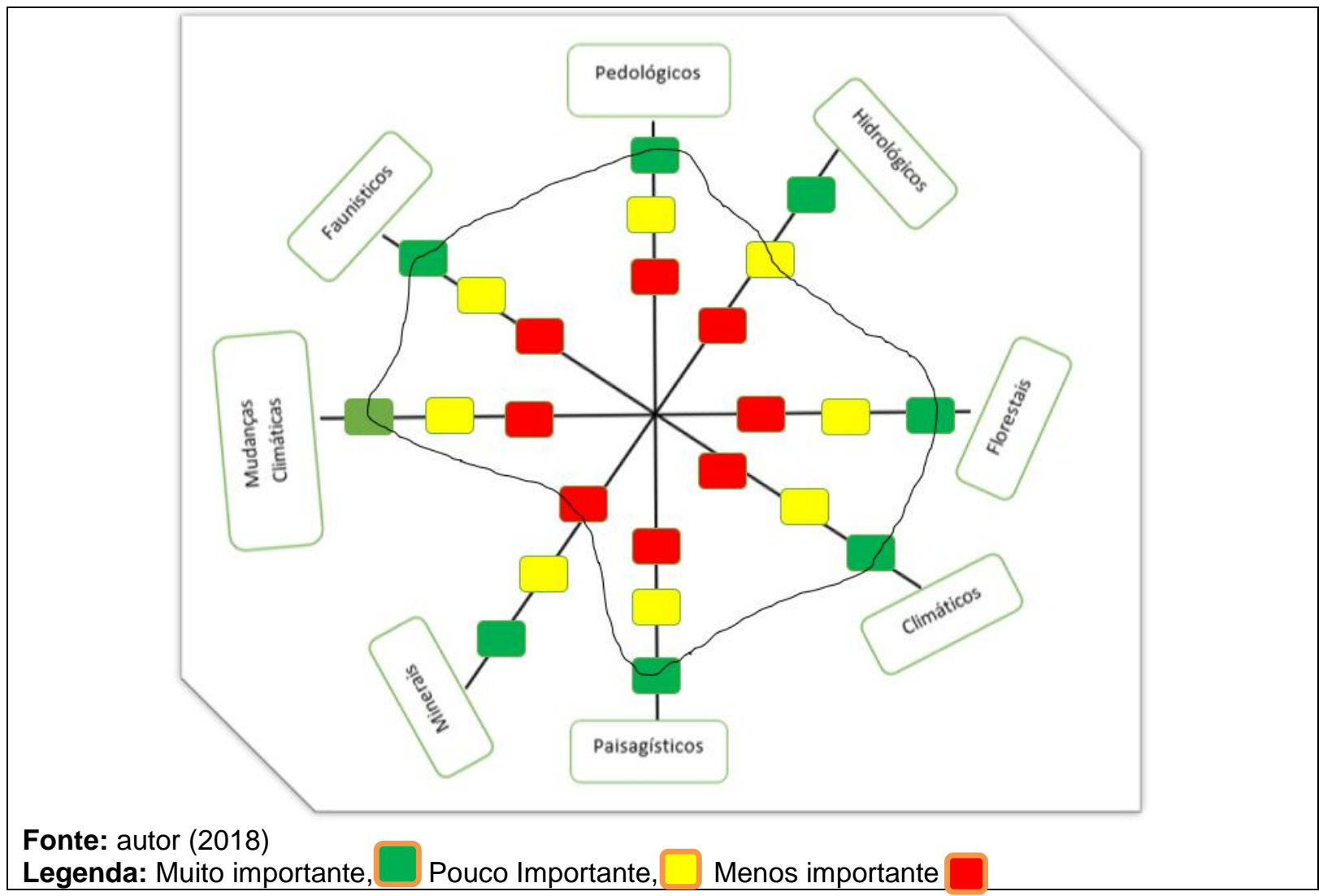

\section{CONCLUSÕES}

O estudo revela que o Distrito de Massinga, não é rica em recursos naturais, dada a sua localização numa bacia sedimentares recente. Existe sim disponíveis alguns recursos a serem capitalizados, o exemplo de calcários e Saibro, assim como os florestais que são usados em grande medida para a construção de habitações à nível Distrital e Provincial. No entanto, Massinga em termos comparativos, é referência Provincial na criação de gado bovino, produção de hortícolas, milho, recursos pesqueiros e destino turístico preferencial. Do ponto de vista da concretização dos ODS, o Distrito dispõe de recursos hídricos (superficiais), que de alguma forma pode ser respondido o Objectivo 6.

Para que as instituições que gerem os recursos naturais a nível provincial e distrital garantam a gestão sustentável dos mesmos, é necessário que estas façam valer as orientações contidas nos documentos orientadores, tais como protocolos internacionais, os Objectivos do Desenvolvimento Sustentável (ODS) e a legislação ambiental nacional. Promover a gestão integrada dos recursos hídricos e biológicos 
entre as instituições públicas e privadas, assim como as iniciativas locais (CGRN). para que se reduzam as incertezas em contextos de mudanças.

\section{REFERÊNCIAS}

AGUIAR et al, in VIEIRA, Toledo e Júnior (orgs). Ambiente e Sociedade na Amazónia: uma abordagem interdisciplinar. Rio de Janeiro: Garamond.. 2014.

ALMEIDA, J.A.G. Os serviços dos ecossistemas na valorização dos espaços agrícolas: perspetivas gerais e aplicação a um território rural de montanha. Dissertação (Mestrado em Ciências e Tecnologia do Ambiente) -Faculdade de Ciências da Universidade do Porto, 2013.

COMISSÃO MUNDIAL SOBRE MEIO AMBIENTE E DESENVOLVIMENTO (CMMAD). Nosso futuro Comum. Rio de Janeiro: Fundação Getúlio Vargas, 1988.

DE ALMEIDA Armando Antunes. Monografia agrícola de massinga (POSTO-SEDE). Lisboa, 1959 .

DOS MUCHANGOS, Aniceto. Paisagens e regiões naturais. Tipografia globo. Maputo. 1999.

GONSALVES, A. Governância colaborativa para a preservação e valorização dos serviços dos ecossistemas e da biodiversidade da Serra da Aboboreira: proposta para uma Gestão Sustentável. Porto, 2011.

HICKMAN JR. et al. Integrated principles of zoology. $11^{\text {th }}$ ed. New York: McGraw Hill Companies, 2001.

INSTITUTO NACIONAL DE ESTATÍSTICA (INE). Estatísticas do distrito de massinga. Maputo, 2008.

LIRA, W.S. CANDIDO, G.A. Gestão sustentável dos recursos naturais: uma abordagem participativa. Campina Grande: Editora Universitária, 2013.

MA. Ecosystems and human, we-being a framework for assessment. Island Press Washington, 2003. Disponível em: http//www.maweb.Org/en/Framework.aspx). Acesso em: 18 abr. 2018.

PEREIRA, et al. Ecossistemas e bem-estar humano: avaliação para Portugal, do millennium ecosytem assessment. Lisboa: Escolar, 2009.

PINNA, $P$, et al. Carta geológica popular de Moçambique escala 1: 1.000.000. Maputo: Instituto Nacional de Geologia (ING). 1987.

REPÚBLICA DE MOÇAMBIQUE. Plano estratégico para o desenvolvimento do sector agrário (PDSA) 2011-2020. Maputo, 2011.

VENTURI, L. A.B. Recurso natural: a construção de um conceito. Revista GEOUSP, n. 20. São Paulo. 2008. 
VONATA, R. H. W. Introdution to payments for ecosystem services: a reference book for Uganda. Forest trends and the Katoomba Group. Uganda. 2011.

Objetivos do desenvolvimento sustentável (ODS) 